\title{
STRUKTUR CERITA WEJANGAN ANEH
}

\author{
A. Aisyah \\ IAIN Raden Intan, Lampung \\ Jalan Letkol Endro Suratmin, Sukarame I, Bandarlampung 35131 \\ email: isyahpananrangi@yahoo.co.id
}

\begin{abstract}
The Structure of Wejangan Aneh Story. This study aimed to describe the composition of Wejangan Aneh story. Research data was sourced from Fajar daily newspaper in Makasssar. Data analysis was done by using critical discourse analysis approach. The results showed that the beliefs of the people about supernatural, which represented by the use of the macro-structure and micro-structure. The central theme of the story is the emergence of the negative cultural ideology. That is the behavior of the villagers who liked to accept foreign cultures that caused negative impact and sin because they missed the attention of doing their worship.
\end{abstract}

\begin{abstract}
Abstrak: Penelitian ini bertujuan mendeskripsikan struktur Cerita Wejangan Aneh. Data penelitian bersumber dari Harian Fajar Makasssar. Analisis data dilakukan dengan pendekatan analisis wacana kritis. Hasil penelitian menunjukkan kepercayaan orang alam gaib yang direpresentasikan dari penggunaan struktur makro dan struktur mikro. Tema sentral dalam cerita tersebut adalah munculnya ideologi kultural negatif, yakni perilaku masyarakat desa meniru budaya dari luar yang hanya memberikan dampak negatif dan dosa karena sudah tidak ada lagi yang memperhatikan ibadahnya.
\end{abstract}

Kata Kunci : analisis wacana kritis, metafora, van Dijk

Karya sastra lahir dari pergulatan pikiran, perasaan, dan pengalaman manusia yang dituangkan melalui sarana bahasa. Bahasa secara umum adalah media komunikasi manusia. Oleh para sastrawan, karya sastra yang dihasilkan dijadikan sebagai media komunikasi dengan manusia lain. Karya sastra juga sebagai salah satu alternatif untuk mencapai dan memenuhi kebutuhan manusia yang bersifat nonmaterial.

Karya sastra lahir dari kreativitas pengarang, dituangkan melalui pikiran dan perasaan. Di dalamnya termuat segala gerak-gerik kehidupan manusia. Karya sastra adalah karya imajinatif. Ia bukan representasi dari kenyataan. Keselarasan yang ada dalam karya sastra tidak secara otomatis berhubungan dengan keselarasan yang ada dalam masyarakat tempat sastra itu dilahirkan.

Sastra yang pada umumnya membahas tentang manusia dalam kehidupan itu, dapat menjadi wadah dan wahana untuk mengekspresikan ide. Ide-ide yang dapat memengaruhi dan mendorong pembacanya sebagai individu dan anggota masyarakatnya untuk menafsir, merenungi, dan meresapi nilai yang terkandung di dalamnya dan mengkajinya dengan nilai yang dianut oleh dirinya dalam rangka mencari jalan ke arah kebenaran (Pradotokusumo, 1984: 157). Kenyataan yang ada pada masyarakat dijadikan acuan untuk membuat cerita yang bersifat imajinatif. Pada dasarnya, karya sastra merupakan hasil karya anak manusia yang kemungkinan kebenaran ceritanya tak dapat diyakini secara nyata. Namun demikian, hal yang nampak dalam sebuah cerita, bukanlah sepenuhnya imajinatif belaka.

Sebagai karya sastra, cerita dipandang dapat mengungkap berbagai peristiwa yang bisa memengaruhi pemikiran pembaca. Di dalamnya dapat memuat suatu ideologi yang dapat membuat pembaca meyakini isi yang disampaikan. Oleh karena itu, cerita dapat dikaji dalam konteks wacana. Wacana merujuk kepada pemakaian bahasa tertulis dan ucapan yang tidak hanya dilihat dari aspek kebahasaannya, tetapi juga bahasa itu diproduksi dan ideologi ada di baliknya. Me- 
mandang bahasa semacam ini berarti meletakkan bahasa sebagai bentuk praktik sosial. Bahasa adalah suatu bentuk tindakan, cara bertindak tertentu dalam hubungannya dengan realitas sosial (Eriyanto, 2001).

Kajian wacana kritis tidak hanya terbatas pada struktur dan proses terbentuknya teks itu saja, melainkan pada semua teks dipandang selalu mengandung ideologi. Ideologi tersebut tercermin dari pemakaiaan kosakata, kalimat, dan tata bahasa. Berdasarkan asumsi tersebut, maka van Dijk membuat kerangka analisis wacana yang dapat didayagunakan. Ia melihat suatu wacana terdiri atas berbagai struktur/tingkatan yang bagian saling mendukung. van Dijk membaginya ke dalam tiga tingkatan, yaitu: (1) struktur makro, (2) superstruktur, dan (3) struktur mikro.

Menurut van Dijk (dalam Eriynto, 2001), struktur makro merupakan makna global/umum dari suatu teks yang dapat dipahami dengan melihat topik dari suatu teks. Tema wacana ini tidak hanya isi, tetapi juga sisi tertentu dari suatu peristiwa. Dari topik, seseorang bisa mengetahui masalah dan tindakan yang diambil oleh komunikator dalam mengatasi masalah tersebut. Tindakan, pendapat, keputusan dapat diamati pada struktur makro suatu wacana.

Superstruktur adalah kerangka suatu teks. Cara struktur dan elemen wacana itu disusun dalam teks secara utuh yang bersifat skematik (alur). Superstruktur terdiri atas pendahuluan, isi, dan akhir wacana (Jufri, 2006). Struktur mikro adalah makna wacana yang dapat diamati dengan menganalisis pilihan kata, kalimat, proposisi, anak kalimat, gaya yang digunakan individu dan komunitas tertentu dikategorikan van Dijk sebagai sesuatu yang bersifat konkret.

Ketiga bagian tersebut, merupakan suatu kesatuan, saling berhubungan. Kerangka wacana van Dijk merupakan bagian integral yang saling mendukung yang memuat struktur wacana, kognisi sosial, dan konteks sosial. Menurut pendapat van Dijk, koginisi sosial merupakan cara pandang seseorang dan suatu komunitas tertentu dan pengetahuan untuk dapat memahami suatu peristiwa yang melahirkan produksi wacana berdasarkan reperesentasi mentalnya. Pilihan kata dan kalimat dipandang sebagai suatu cara untuk memengaruhi pendapat umum, menciptakan dukungan, mempertahankan legitimasi, dan memarjinalkan komunitas yang lain. Di dalamnya memuat suatu informasi tertentu yang bersifat ideologis (Jufri, 2006).
Menurut Jufri (2006), pada hakikatnya wacana dipandang sebagai sesuatu yang bertujuan memengaruhi, mendebat, membujuk, menanggapi, menyarankan, atau memperjuangkan. Wacana dipahami sebagai sesuatu yang diekspresikan secara sadar dan terkontrol, bukan sesuatu yang di luar kesadaran. Dengan konsep tersebut, wacana dipahami sebagai suatu bentuk interaksi. Penulis menggunakan bahasa untuk berinteraksi dengan pembaca, pendengar, atau mitra tutur.

Cerita yang di dalamnya memuat peristiwa, latar, amanat, dan partisipan sangat relevan jika dikaji dengan analisis wacana kritis. Kajian kewacanaan yang berhubungan hal itu, meliputi: topik, partisipan, waktu dan tempat, situasi, komunikasi, kode, situasi komunikasi, budaya, atau adat istiadat berkomunikasi.

Kajian wacana yang tepat digunakan dalam menganalisis cerita adalah model van Dijk yang memuat struktur makro, superstruktur, dan struktur mikro. Elemen-elemen yang dimiliki van Dijk akan dieksplanasi secermat mungkin untuk memperoleh hasil kajian yang bagus.

Wejangan Aneh adalah cerita yang mengisahkan tentang seorang anak yang kemasukan arwah neneknya yang sudah meninggal dunia dua tahun sebelumnya. Arwah nenek tersebut dikisahkan dalam cerita ini untuk memberikan wejangan kepada anak cucunya, serta warga masyarakat yang mendiami desa. Hal ini terkait karena masyarakat desa yang sudah tidak lagi melakukan ritual tertentu karena dipengaruhi oleh kebudayaan modern. Ritual yang ditinggalkan, misalnya sudah tidak ada lagi yang membawa sesajen (pa'roppo) ke pantai dan kurangnya masyarakat yang memenuhi masjid untuk beribadah. Dari segi budaya, kejadian seperti ini sering terjadi hingga menggeser sebagian nilai-nilai budaya yang sudah sekian lama dijalani oleh masyarakat desa Galesong.

Penelitian ini bertujuan mendeskripsikan ideologi kultural yang terkandung dalam wacana cerita. Ideologi kultural tersebut direpresentasikan dalam berbagai bentuk pilihan bahasa yang terdapat dalam wacana.

\section{METODE}

Penelitian ini adalah penelitian kualitatif. Lebih khusus, jenis penelitian menggunakan analisis wacana kritis. Data bersumber dari 
Harian Fajar Makassar. Pengumpulan data dilakukan melalui metode dokumentasi. Penggunaan metode dokumentasi disesuaikan dengan karakteristik data penelitian yang berwujud data tertulis. Data yang berupa kalimat dikumpulkan dengan teknik baca-kutip. Peneliti bertindak sebagai pengumpul dan pengolah data. Untuk membantu peneliti, didayagunakan panduan analisis untuk menampung data penelitian.

Berdasarkan metodologi yang digunakan, proses analisis menggunakan elemen wacana van Dijk yang terdiri atas superstruktur, struktur makro, dan struktur mikro. Untuk menjamin keabsahan data penelitian, pengecekan keabsahan data dilakukan melalui objektivitas (confirmability) dan kesahihan internal (credibility). Untuk mencapai kondisi objektif, peneliti (1) mengaji literatur yang relevan, (2) menetapkan fokus penelitian yang tepat, (3) instrumen dan cara pengumpulan data yang akurat, dan (4) analisis data secara benar

\section{HASIL DAN PEMBAHASAN}

\section{Superstruktur Cerita Wejangan Aneh}

\section{Bagian Awal}

Pada bagian awal cerita, tema yang dapat diperoleh dari persitiwa adalah kebudayaan yang mulai luntur karena dipengaruhi oleh zaman. Hal tersebut dapat terlihat pada kutipan berikut.

Di sampingku berdiri sosok lelaki yang pakaiannya aneh menurutku. Bajunya bersih tapi banyak sekali yang ditempel. Mungkin dia tidak bisa beli baju baru sehingga bajunya yang robek ditempeltempeli. Lain lagi celananya, tidak sampai ke atas sehingga boxernya kelihatan. Selain itu, bagian bawah celananya sangat kecil. Mungkin dia tidak punya cukup uang untuk membeli celana sehingga dia memakai celana adiknya untuk bepergian. Lulu pun heran memikirkan zaman, entah aku yang terbelakang atau mereka yang terlalu prematur untuk mengerti mode.

Berdasarkan hasil analisis di atas, ditemukan bahwa kebudayaan yang sejak turun-temurun tercipta di desa sudah hampir tergeser oleh budaya-budaya dari luar. Sesuatu yang baru selalu membuat orang untuk mau mencobanya mes- kipun itu memberikan dampak negatif bagi kita nantinya.

\section{Bagian Tengah}

Pada bagian tengah cerita, tema yang ditemukan, yaitu wejangan. Hal tersebut tergambar pada kutipan berikut.

\begin{abstract}
Mentari kelihatan seperti orang bangsawan memakai songkok guru dan lipa' sabbe dia duduk bersila penuh karisma dan memberi wejangan kepada kami semua agar jangan melupakan budaya Desa Galesong. "Kau Rudi, tidak pernah lagi kulihat ikut ayahmu ke pantai bawa pa'rappo (sesajen). Sekarang kau lihat kan? Ayahmu tidak pernah lagi mendapatkan rezeki yang banyak. Kau lebih memilih ikut budaya orang lain dibandingkan budayamu sendiri. Bukan hanya Rudi, kalian semua juga jangan pernah meninggal-kan rumah (masjid) yang telah kalian bangun di tengah lapangan. Penuhilah rumah itu, agar desa kita jauh dari musibah".
\end{abstract}

Berdasarkan hasil analisis ditemukan bahwa Mentari kemasukan roh neneknya. Pada saat kemasukan nenek memberikan wejangan kepada anak cucunya beserta masyarakat yang ada di desa. Ini sering terjadi dalam lingkungan masyarakat terkadang orang yang kemasukan tersebut biasanya ada yang memberikan suatu petuah kepada kita dan ada pula yang hanya menyakiti orang yang dimasukinya.

\section{Bagian Akhir}

Pada bagian akhir, tema yang ditemukan adalah masyarakat yang kembali memiliki kesadaran religius. Hal tersebut terlihat pada kutipan berikut.

Lagi-lagi terjadi keanehan, bangunan megah yang sering kukunjungi kini memiliki penghuni yang cukup banyak. Betapa tidak, malam ini pasar malam belum berakhir. Tapi masyarakat lebih dulu ke masjid untuk shalat berjamaah. Jauh berbeda dengan semalam. Entah apa yang membuat mereka mengunjungi masjid. Apakah kesadaran akan perintah Tuhan ataukah sekadar 
mengikuti perintah nenekku yang semalam memberi wejangan.

Berdasarkan hasil analisis ditemukan bahwa warga masyarakat mulai mendahulukan kepentingan akhirat untuk beribadah kepada Sang Pencipta baru memikirkan kepentingan akan dunianya. Fenomena yang sering ditemukan, ketika adzan berkumandang di masjid, sering kali masih ada warga yang lebih mendahulukan kepentingan dunia daripada akhirat.

\section{Struktur Mikro Cerita Wejangan Aneh}

\section{Representasi Ideologi Kultural dalam Tampilan Aktor/Pelaku}

Pelaku dalam cerita Wejangan Aneh, yaitu: (1) Lulu, (2) Mentari, (3) Nenek, (4) Dg. Bulang, (5) Dg. Ngitung, dan (6) Rudi. Gambaran pelaku dapat diperhatikan sebagai berikut. Lulu digambarkan sebagai pelaku utama dalam cerita. Lulu sebagai pelaku utama dicirikan sebagai orang yang mengikuti sistem struktur sosial yang mengindahkan akan adanya hukum karma/alam. Lulu berkeyakinan bahwa masyarakat masih memiliki fungsi dalam kehidupannya dan setiap orang harus mematuhi sistem tersebut jika ingin terhindar dari hukum alam pencipta. Perbuatan yang dilakukan Lulu merupakan contoh bagi untuk tetap melestarikan budaya dan selalu taat beribadah kepada Allah Swt. Hal tersebut ditunjukkan melalui kutipan berikut.

Pada waktu sore menjelang magrib, pada waktu itu Lulu sedang duduk di atas singgasana hamparan pasir Galesong memandangi sunset. Tak lama kemudian adzan berkumandang yang beberapa saat kemudian Lulu pun berangkat ke masjid di mana masjid yang megah itu hanya dihuni oleh segelintir anak belasan tahun dan orang tua saja. Di sampingku berdiri sosok lelaki yang pakaiannya aneh menurutku.

Bajunya bersih tapi banyak sekali yang ditempel. Mungkin dia tidak bisa beli baju baru sehingga bajunya yang robek ditempel-tempeli. Lain lagi celananya, tidak sampai ke atas sehingga boxernya kelihatan. Selaian itu, bagian bawah celananya sangat kecil. Mungkin dia tidak punya cukup uang untuk membeli celana sehingga dia memakai celana adiknya un- tuk bepergian. Lulu pun heran memikirkan zaman, entah aku yang terbelakang atau mereka yang terlalu prematur untuk mengerti mode.

Ideologi kultural yang dikonstruksi dari wacana Wejangan Aneh berbentuk hukum alam yang masih dipercayai kekuatannya. Dalam tradisi masyarakat desa, seseorang yang tidak melakukan ibadah kepada Allah Swt. akan mendapatkan teguran, yaitu berupa musibah yang akan menimpah desa tersebut. Agar mendapatkan rezeki yang berlimpah, ada tradisi yang harus dilakukan oleh warga. Mereka harus membawa sesajen ke pantai agar mendapatkan rezeki yang berlimpah. Data ditunjukkan pada kutipan berikut.

"Kau Rudi, tidak pernah lagi kulihat ikut
ayahmu ke pantai bawa pa'rappo (sesa-
jen). Sekarang kau lihat kan? Ayahmu ti-
dak pernah lagi mendapatkan rezeki yang
banyak. Kau lebih memilih ikut budaya o-
rang lain dibandingkan budayamu sendiri.
Bukan hanya Rudi, kalian semua juga
jangan pernah meninggalkan rumah (mas-
jid) yang telah kalian bangun di tengah la-
pangan. Penuhilah rumah itu, agar desa
kita jauh dari musibah".

\section{Representasi Ideologi Kultural dalam Me- tafora}

Penciptaan metafora dalam wacana menjadi hal yang menarik karena mengandung kiasan atau ungkapan yang dapat merepresentasikan makna suatu teks. Dalam wacana Wejangan A$n e h$, terdapat beberapa metafora yang memiliki ideologi kultural. Penggunaan metafora ditunjukkan pada data berikut.

Tak seperti minggu lalu saat aku ke mari, mataku masih puas memandang telanjang laut lepas mengiringi kepergian sang surya.

Hal itu karena sekarang dewi malam diamdiam mulai mengintip kehidupan malam di Galesong.

Tapi ketika aku masuk, kadang-kadang lekukan-lekukan kaligrafi di dinding bangunan itu menyaksikan jeritan jiwaku. 
Hatiku geli mendengar bualan anak muda tadi, seakan-akan dia pernah negosiasi dengan Tuhan tentang ibadah.

Mataku liar dan kudapati sosok lelaki yang tadi sore bertemu denganku di masjid tengah berada dalam kerumunan itu.

Lagi-lagi terjadi keanehan, bangunan megah yang sering kukunjungi kini memiliki penghuni yang cukup banyak.

Berdasarkan paparan data, dapat diklasifikasikan makna yang terkandung dalam: (1) memandang telanjang laut lepas mengiringi kepergian sang surya maksudnya melihat secara jelas atau nampak keindahan diwaktu senja tiba; (2) dewi malam diam-diam mulai mengintip merupakan gaya bahasa personifikasi yang menganggap sesuatu benda mati seolah-olah hidup, yang dilambangkan sebagai bulan; (3) lekukan-lekukan kaligrafi maknanya tulisan arab yang menghiasi dinding masjid dan jeritan jiwaku maknanya kesedihan; (4) hatiku geli maknanya tertawa dalam hati dan bualan artinya pembicaraan yang tidak ada artinya atau tidak masuk akal; (5) negosiasi dengan Tuhan diartikan melakukan proses tawar menawar dengan jalan berunding kepada Tuhan yang mana kata negosiasi dengan Tuhan; (6) bangunan megah disimbolkan sebagai masjid tempat untuk beribadah.

Berdasarkan data linguistik metafora yang ada dalam Wejangan Aneh, pengarang melalui metafora ingin memengaruhi pembaca dan menciptakan kesan yang mendalam di hati pembaca cerita ini. Pengarang ingin mengonstruksikan suatu ideologi kepada pembaca tentang suatu kebenaran arti kepercayaan dan kebesaran yang dimiliki Allah Swt.

\section{PENUTUP}

Berdasarkan pembahasan, dapat disimpulkan bahwa hakikat yang dikonstruksikan dalam ideologi kultural Wejangan Aneh adalah kebenaran adanya kepercayaan orang mengenai alam gaib yang direpresentasikan penggunaan struktur makro dan struktur mikro. Superstruktur membentuk skematik yang runtut yang terdiri atas bagian awal, bagian tengah, bagian akhir. Pada bagian awal, tema yang ditemukan adalah budaya lokal yang mulai luntur karena dipengaruhi oleh zaman. Pada bagian tengah berisi wejangan. Pada bagian akhir cerita dikisahkan masyarakat kembali ke budaya.

Tema sentral dalam cerita tersebut adalah munculnya ideologi kultural negatif, yakni perilaku masyarakat desa meniru budaya dari luar yang hanya memberikan dampak negatif dan dosa karena sudah tidak ada lagi yang memperhatikan ibadahnya. Perilaku ini dipandang akan mendatangkan musibah dari alam. Struktur mikro berupa tampilan aktor dan penciptaan metafora yang memuat kebenaran nilai-nilai budaya yang masih tetap dipertahankan.

\section{DAFTAR PUSTAKA}

Eriyanto. 2001. Analisis Wacana: Pengantar Analisis Teks Media. Yogyakarta: LKiS.

Jufri. 2006. "Struktur Wacana Lontara La Galigo." Disertasi. Malang: Program Pascasarjana Universitas Negeri Malang.
Jufri. 2008. Analisis Wacana Kritis. Makassar: Badan Penerbit UNM.

Pradotokusumo, Partini Sarjono. 1986. Karya Sastra Kakawin Abad Ke-20: Suntingan Naskah serta Telaah Struktur, Tokoh dan Hubungan Antarteks. Bandung: Binacipta. 